\title{
Reflexiones de las autoras y la coordinadora sobre el debate
}

María Cristina Valdez, Marcela Amador Ospina, Julieta Paredes, Silvana Sciortino and Mariana Daniela Gómez

\section{OpenEdition}

Journals

\section{Electronic version}

URL: http://journals.openedition.org/corpusarchivos/1872

DOI: 10.4000/corpusarchivos.1872

ISSN: 1853-8037

\section{Publisher}

Diego Escolar

\section{Electronic reference}

María Cristina Valdez, Marcela Amador Ospina, Julieta Paredes, Silvana Sciortino y Mariana Daniela Gómez, "Reflexiones de las autoras y la coordinadora sobre el debate », Corpus [En línea], Vol. 7, No 1 | 2017, Publicado el 03 julio 2017, consultado el 03 mayo 2019. URL : http://

journals.openedition.org/corpusarchivos/1872 ; DOI : 10.4000/corpusarchivos.1872

This text was automatically generated on 3 May 2019.

Licencia Creative Commons: Atribución-NoComercial 2.5 Argentina (CC BY-NC 2.5 AR) 


\title{
Reflexiones de las autoras y la coordinadora sobre el debate
}

\author{
María Cristina Valdez, Marcela Amador Ospina, Julieta Paredes, Silvana \\ Sciortino and Mariana Daniela Gómez
}

\section{Segunda parte}

\section{María Cristina Valdez}

\section{Introducción}

1 Celebro, agradezco y destaco el interés de la revista Corpus de proponer un debate sobre mujeres indígenas y feminismo. Pues en la interfase de estos términos y su materialidad se expresa el devenir de un habitar descolonial e intercultural para sociedades como las latinoamericanas que no pueden negar su diversidad.

2 Los escritos de este debate, corriendo el riesgo de forzar la clasificación, pueden pensarse en dos líneas. Unos, centrados en mostrar reflexiones resultantes de investigaciones que, aunque no trabajan específicamente el eje del debate, muestran las formas en que las mujeres indígenas piensan su participación política en el movimiento indígena de los pueblos a los que pertenecen. $Y$ los otros, focalizados en los aportes que las reflexiones y prácticas de las mujeres indígenas pueden realizar al feminismo y al género.

3 En esta última perspectiva ubico mi trabajo y el de Julieta Paredes, con quien comparto una pretensión disruptiva en las discusiones con el feminismo hegemónico al interesarnos en expresar nuestras propias construcciones conceptuales; entendiendo que allí está la posibilidad de trazarnos un lugar en este debate y también en el interior de los movimientos indígenas y sociales de pertenencia. También comparto con las autoras de los otros dos trabajos del debate algunos puntos, los que considero pertinente presentar para matizar lo que podríamos llamar un feminismo no hegemónico en perspectiva descolonial que surge de la práctica cotidiana de lucha de las mujeres indígenas. El primero de esos puntos es destacar la interseccionalidad de las opresiones a las que están 
sujetas las mujeres originarias, las cuales no pueden jerarquizarse o privilegiarse una por encima de otra, un punto que cuestiona el pensamiento dicotómico y compartimentado de la racionalidad moderna. El segundo, y relacionado con el primero, la necesidad de contextualizar e historizar la experiencia de subordinación y su especificidad en el caso de los pueblos indígenas. Respecto de lo cual subrayo los sentidos y significados construidos en la proyección de los pueblos. Aquí ubico las discusiones en torno a las nociones indígenas de complementariedad y dualidad para referirse a las relaciones de género. En tercer lugar, el carácter situado de las reflexiones compartidas en los escritos. Esta postura se expresa en las interpelaciones que nos realizan nuestras interlocutoras y que pueden designarse como parte de una "antropología por demanda", así como los lugares en que nos ubicamos para construir nuestros relatos pensando en nuestros interlocutores. En relación a este punto se destaca el esfuerzo de las autoras por compro/ meterse en la escritura, manifestándose en la referencia a un nosotras colectivo que permite inferir su posicionamiento. Finalmente, un cuarto aspecto común a los escritos es el reconocimiento del quehacer y el devenir de las mujeres indígenas que se plasman en un proyecto político, epistemológico y creativo; sea a partir de la construcción de un pensamiento propio, como de la trasformación de los lazos de unidad, o de la configuración de un constructo político que disputa los sentidos de la maternidad. En este punto es en el que propongo centrar el debate, entendiendo que la dimensión político epistemológica es la que define una resolución creativa y afirmativa de las identidades de las mujeres como colectivo.

\section{Complementariedad}

Retomo la indicación de la necesidad de historizar la experiencia de subordinación y, en correspondencia, leer en clave de construcción el devenir de las mujeres indígenas en los proyectos políticos y epistemológicos de los que son parte. Para el asunto que nos preocupa en esta oportunidad -los diálogos posibles entre el conocimiento de las mujeres indígenas y el feminismo- considero que solo es posible si se asume una decisión política real. Esta decisión requiere conferir estatuto de saber a aquellos conocimientos que históricamente han sido subordinados. Refiero a estas cuestiones en este apartado porque leo en los trabajos de Marcela Amador Espinosa y Silvana Sciortino un posicionamiento crítico acerca del sentido indígena de la noción de complementariedad.

Comparto con las autoras la mirada crítica y de sospecha alrededor de determinadas categorías utilizadas para legitimar prácticas como la violencia y la subordinación de las mujeres en las organizaciones indígenas. Lo que interpreto es que las autoras identifican el recurrir a la cosmovisión como un procedimiento cosificador no emancipador. Sin negar que esto pueda acontecer, o que en determinadas circunstancias esto sea lo que sucede, no necesariamente se corresponde con lo que las mujeres indígenas deseamos que acontezca, en tanto los deseos no son homogéneos. Quiero decir que los conceptos de complementariedad y dualidad son conceptos con los cuales disputamos sentidos al interior de los movimientos y organizaciones indígenas y en diálogo hacia afuera. Esto debe ser entendido en paralelo a la consideración de que la memoria es también un campo de disputa atravesado por diferencias de género y generación.

Al respecto, el primer trabajo compartido define las implicancias de la colonialidad que incluyen el silenciamiento, la apropiación y la subordinación del mapuce kimvn así como la des-subjetivación del mismo. En este sentido, es nuestra obligación iniciar una 
descolonización al interior del pueblo mapuce específicamente en las nociones que nos habilitan a la comprensión de la vida social. En respuesta a este objetivo se cuestionan los sentidos comunes y generalizados de las nociones de dualidad y complementariedad. Por un lado, se reconoce la existencia del género en la sociedad mapuce precolonial, afirmación que va en contra de la idea de la simetría de género que tanto gusta escuchar y decir cuando se da a conocer la "cosmovisión indígena". Asimetría constitutiva que no puede reconocerse sin ponderar su intensificación a partir de la colonización, menos negando la imposibilidad que las influencias benéficas aportadas por los indígenas han tenido para volverse legitimas. Por otro, se sugiere revisar las nociones propias, la dualidad no es oposición como lo racionaliza el pensamiento dicotómico moderno. Lo dual incluye la ambivalencia, la movilidad y la transitoriedad. Y quizás algo fundamental es que en lo que a procesos de constitución de identidad refiere, dualidad excede a la humanidad.

Considero que académicas intelectuales y activistas deberían preguntarse por qué estamos leyendo de esta manera y no de otra la realidad que estudiamos. En otros términos: ¿para qué nos sirve? ¿A qué fines responde la interpelación del posicionamiento y justificación en la cosmovisión que se realiza presurosamente a los indígenas, en este caso a las mujeres? Puede ser que opere una limitación para pensar en y desde otro encuadre cosmovisionario y conceptual que lxs ubica en un lugar específico de la discusión. Particularmente creo que hay serios inconvenientes asociados a la traducción. Tener que traducir al castellano vacía de contenido filosófico y político el pensamiento (rakizuam). Sin embargo, la traducción es ineludible y nos ubica en el dilema de tener que explicar (nos) permanentemente y de resignificar la trama de sentidos hegemónica con el riesgo de quedar atrapados en los significados que el poder lingüístico hegemónico les adjudica. Ciertos términos, como por ejemplo "naturaleza", al ser traducidos quedan encapsulados en un sistema conceptual eurocéntrico, patriarcal y racista. A los indígenas, y en particular a las mujeres, se nos cuestiona el uso de categorías propias para defender nuestras posturas, sea por su conservadurismo o falta de sustento en fuentes históricas que evidencien su autenticidad, ubicándonos en el deber moral de otorgar la mayor claridad y criticidad a la lucha que intentamos llevar adelante. En este sentido, es menester por parte de lxs académicxs e intelectuales no indígenas la escritura de otra historia, porque es bien difícil trabajar en base a un corpus documental que fue escrito desde un determinado lugar que es el del saber hegemónico occidental. A lo que sigue también preguntarnos: ¿a quién le corresponde la descolonización del conocimiento? Debemos hacernos cargo del lugar que ocupamos en la producción de conocimiento por los efectos que esto tiene en la vida de las personas.

\section{Un lugar para las mujeres indígenas}

Quiero subrayar el hecho de que la igualdad jurídica y de derechos entre mujeres y hombres no resuelve los problemas que son tan tangibles en este momento de la historia. Tan habituados estamos a la violencia ensañada con las mujeres y sus cuerpos que ya no nos sorprende que en Waj Mapu asesinen una mujer cada menos de 30 horas. Menos sensibiliza y preocupa la muerte, también frecuente, de mujeres mapuce como consecuencia de un modelo neodesarrollista como el que ya existe en "Vaca muerta", territorio ancestral mapuce. Modelo económico que también define "modelos de vida", en el que se interseccionan prácticas de extractivismo salvaje sobre el cuerpo-territorio, pero también luchas contra un sistema neocolonial racista, patriarcal y capitalista. 
Entonces, la disputa de sentidos sobre las concepciones propias para entender el género no puede pensarse desde el interés inmediato de igualdad entre los géneros en los términos que lo concibe la concepción liberal. Las mujeres mapuce deseamos y apostamos por construir "un lugar para nosotras", y en lo inmediato estamos preocupadas por mejorar nuestras condiciones de existencia para, desde allí, pensar en la posibilidad de un diálogo intercultural. Recurrir a la memoria histórica sirve a los fines de anclar la perspectiva de género mapuce en una base que se sirve de la cosmovisión; la cual no es inmutable y está congelada en el pasado sino sujeta a los vaivenes de la historia.

Podría afirmar, junto con Marcela Amador Espinosa, que una de las apuestas como mujeres indígenas es la "interpelación del discurso organizativo" para visibilizar la dimensión construida y siempre cambiante de los pueblos, su cultura y conocimientos. Es pertinente señalar que cuando se plantean discusiones vinculadas al lugar de las mujeres en las organizaciones indígenas, estas se ponderan de manera negativa como una distracción de las prioridades y, como lo sugiere la autora mencionada, como una amenaza a la unidad. Esta es una lectura o al menos una de las posibles lecturas de lo que sucede. Otra es la que sostienen quienes llevan adelante esta interpelación, que pueden leerla como una instancia de transformación y de reconcentración de los esfuerzos. En mi caso sostengo que concentrar los esfuerzos de la lucha en resolver cuestiones vinculadas a las mujeres, a sus cuerpos y deseos puede habilitar una retórica y una práctica más abarcativa, flexible y, por qué no, más radical en términos de su potencial. Como sostiene Machao Aráoz (2014):

Pese a todo, mal que les pese a burócratas de Estado y a inversionistas, todavía hay en estas Tierras, cuerpos que, pese a tanta violencia, a tantas agresiones históricamente acumuladas, sienten en 'carne propia' la devastación de los territorios... Son aquellos que no 'entienden' la lógica de la compensación, pues creen que ciertos bienes están fuera de lo 'negociable'... Son cuerpos-sujetos de sensibilidades-sociabilidades otras.... Portadores de afectividades radicalmente otras...Potencialmente alumbradoras, por tanto, de otros mundos posibles.

11 En esta trayectoria se inscriben los procesos de educación y salud intercultural que llevan a cabo las comunidades mapuce en Neuquén. Particularmente el fortalecimiento y recuperación de la educación autónoma mapuce a partir de la realización de una multiplicidad de ceremonias que intervienen en los diferentes momentos del devenir de las personas. En estas ceremonias se pone en juego la ancestralidad, vigencia, proyección e innovación del mapuce kimvn y se permea la configuración de subjetividades y relaciones de género diferentes.

\section{Reflexiones: segunda parte}

\section{Marcela Amador Ospina}

12 La segunda parte del debate sugerido nos invita a entretejer nuestras reflexiones sobre la relación entre las mujeres indígenas y los feminismos, profundizando en los diálogos, encuentros, tensiones y posicionamientos en el amplio repertorio de posibilidades que parece configurar tal relación. El uso gramatical del plural para conectar tres significantes (mujeres-indígenas-feminismos) anticipa el lugar de enunciación desde el cual fuimos invitadas por Mariana Gómez a intervenir en un diálogo incipiente, problemático, frágil, complejo, inconcluso y fascinante a través de nuestras experiencias 
de investigación y acción política. No es un dato menor que la sintonía del debate propuesto también esté generizada y apele a entablar un diálogo en femenino, basado en la curiosidad y, por momentos, despojado de la confianza, siempre esquiva y necesaria para construir nuevas relaciones.

Desde diferentes aproximaciones, el debate en su conjunto expresa, erige y traza presencias que interpelan ausencias, enfrentando la perplejidad que nos ha causado el silencio social, político y académico sobre las vidas y experiencias de las mujeres, siempre diversas, siempre heterogéneas.

Las intervenciones de quienes participamos en este debate posibilitan varias reflexiones. Cada una presenta un esfuerzo de comprensión situada de nuestras experiencias de investigación y acción política, interpelando la construcción de una frontera trazada por la pretensión de neutralidad positivista que busca separarlas. Son experiencias corporizadas, encarnadas, construidas en el marco de diálogos intersubjetivos entre mujeres diversas, con inserciones personales, profesionales y académicas diferentes y con pertenencias nacionales también disímiles. Tal vez eso explica que ninguna pudo, quiso ni aceptó "ir al grano" de la discusión, porque coincidimos en que "el grano" no lo es en tanto no se lo entiende y aborda como un proceso de comprensión constituido por y constitutivo de nuestras propias trayectorias y experiencias como mujeres comprometidas con las luchas de otras mujeres y también con las nuestras.

15 Tanto Silvana Sciortino, Cristina Valdez, Julieta Paredes y yo coincidimos en enfatizar que nuestra aproximación está constituida y atravesada por una perspectiva experiencial, así como en reiterados esfuerzos para construir nuestras propias prácticas de descolonización. En el proceso de andar y desandar nuestros lugares de enunciación, partimos de que el cuerpo es el lugar de la experiencia y apuntamos a sugerir las maneras en que los sistemas de dominación están articulados. De allí que insistamos en la importancia de caracterizar de manera más aguda los modos en los que patriarcado/ racismo/colonialismo/sexismo/clasismo devienen articulaciones fundamentales para la comprensión de las violencias hacia las mujeres.

Esto no significa, en cualquier caso, que nuestros compromisos sean los mismos; que nuestras concepciones sobre el campo académico del que algunas de nosotras provenimos sean las mismas; que las maneras en las que buscamos construir un vínculo siempre esquivo y cargado de un manto de sospecha entre la academia y las luchas populares sean las mismas y que las posiciones que ocupamos tanto ahí como en el campo de las luchas populares que apoyamos sean las mismas. Este análisis comparativo, no obstante, ameritaría mayor discusión y una extensión que por ahora resulta imposible. Es probable que esta sea una línea necesaria de indagación para continuar profundizando el debate sobre la posibilidad de construir puentes de diálogo entre las mujeres indígenas y las feministas desde una perspectiva social, cultural e históricamente situada.

17 Por ahora, me interesa darle continuidad a algunos de los asuntos que abordé en la primera parte de este debate, guiada por las coincidencias y divergencias que encuentro con las contribuciones realizadas por las colaboradoras que participan del debate.

Desde diversas perspectivas y campos disciplinares, los estudios sobre "violación sexual" perfilan, sugieren e hilan, como mínimo, cuatro nudos y debates: el primero oscila entre la construcción de una subjetividad basada en el sujeto "víctima" y el sujeto como "agente"; el segundo es la pregunta por la destrucción o no de la persona y la subjetividad a raíz de la violación sexual; el tercero es el debate entre la posibilidad de comunicar y 
narrar la experiencia de la violación sexual o enfrentarse a lo inenarrable; y el cuarto, vinculado con la pregunta por la profundidad histórica del patriarcado, lleva también a cuestionarse por la profundidad histórica de la violación sexual. Este último nudo es central en la discusión sobre violación sexual en pueblos indígenas y remite, obviamente, a una discusión sobre relaciones de género en pueblos indígenas, un asunto que atraviesa las cuatro intervenciones. ${ }^{i}$

Precisamente, para generar "un espacio semántico de comprensión propia de los significados corporalizados", como lúcidamente lo sugirió Julieta Paredes, coincidimos en la importancia de partir de un análisis de género culturalmente situado. Para ello, también sería fundamental profundizar en una línea de indagación que sitúe el análisis sobre los diálogos, tensiones y negociaciones entre las mujeres indígenas y los feminismos (y feministas) en la heterogeneidad de experiencias sociales, históricas, políticas, económicas y culturales que supone hablar de América Latina. Por eso cuando Mariana Gómez nos preguntó: “¿Serían las mujeres zapatistas y su Ley Revolucionaria lo más cercano a un feminismo indígena deseado ya que allí se conjugarían de manera armónica y justa los derechos de las mujeres con los derechos colectivos de los pueblos indígenas?", yo me atrevería a decir que no.

20 La lectura comparada de los trabajos de quienes participamos en el debate nos encamina a recorrer los diversos marcos interpretativos en los que se inscribe el análisis sobre las relaciones de género en los pueblos indígenas. Allí, de una manera $u$ otra, todas nos enfrentamos a la caracterización de dichas relaciones a partir del principio de complementariedad.

21 En el caso que vengo analizando, es necesario señalar que en sus referencias constantes al proceso de "conformar la familia" o "formar el hogar", las mujeres nasa de dos generaciones ordenaron su propia experiencia en relación con el papel de las violencias en su vida cotidiana. A lo largo de la investigación, entendí los modos en los que el discurso de la familia se funda en la historia de un régimen de heterosexualidad obligatoria, el cual expone el principio de la complementariedad como un marcador que debería regular la vida social y cultural nasa. Como este discurso no es primordial en el tiempo, sino que tiene un autor contemporáneo, es fundamental comprenderlo en su dimensión histórica, así como en su proceso de constitución y reconfiguración en el marco de diálogos e intercambios interculturales entre diferentes sujetos ubicados de maneras desiguales en el escenario. En ambos asuntos coinciden también Paredes y Valdez, mientras que Sciortino parece despojar de historicidad el concepto de complementariedad. ¿Qué implicaciones tiene que las mujeres de diferentes pertenencias étnicas y trayectorias socioculturales circulen por diferentes escalas y dialoguen? ¿En qué condiciones ocurren dichos diálogos? ¿Cómo producen, adoptan, reconstituyen, disputan y adaptan mutuamente el concepto de complementariedad y ante qué interlocutores lo enuncian?

Como he sugerido antes, las experiencias de violencias de las mujeres nasa obliteran el discurso organizativo de la complementariedad, una construcción que ha sido culturalmente adoptada, adaptada y co-producida en el marco de diálogos e interacciones interculturales que han tenido lugar en el proceso de recuperación y fortalecimiento cultural emprendido por los y las nasa durante los últimos treinta años. A diferencia de lo que ocurre en Mesoamérica y los Andes peruanos y bolivianos, el tema de la complementariedad no está desarrollado en la literatura sobre pueblos indígenas en Colombia, y la realidad empírica muestra un abismo con el discurso organizativo. Por 
algunos comentarios que escuché durante el proceso de investigación, valdría la pena explorar en profundidad las trayectorias de algunos intelectuales nasa que estudiaron en Bolivia y tuvieron contacto con estas ideas.

"Ordenar la casa" es una expresión que usan con frecuencia las mujeres y hombres nasa para referirse a la existencia de problemas internos a los que es necesario darles solución. Apelar a esta metáfora familiar es una forma de instituir y legitimar el ejercicio de autoridad y la jerarquía etárea y de género en la que se basa. La identificación y definición de estos problemas son diferenciales según el género y la edad. En particular, en relación con la violación sexual intracomunitaria e intradoméstica, al igual que la mayoría de hombres, muchas mujeres señalaron que "nosotros tenemos que organizar acá adentro" porque "yo a mi cultura no la voy a poner en cuestionamiento". Al referirse a este tipo de violencias, "organizar acá adentro" u "ordenar la casa" implica el reconocimiento de esto como un problema, aunque define los límites de su discusión y resolución: internamente, "dentro de la casa", que es por extensión la comunidad y la organización, "porque yo a mi cultura no la voy a poner en cuestionamiento" y, mucho menos, ante un otro externo. Aun cuando esta es una tendencia que caracteriza la postura de varias compañeras, tampoco es la única, lo cual sugiere que las mujeres nasa no pueden ser comprendidas como un grupo homogéneo y libre de contradicciones. Precisamente, es frente a esta postura que se erigen los reclamos y reivindicaciones de aquellas compañeras que en la actualidad tienen entre 35 y 55 años y quienes han decidido situar y visibilizar sus experiencias de violencias intradomésticas e intracomunitarias, definiéndolas como un problema que las afecta y realizando el trabajo cotidiano que conlleva luchar contra ellas.

24 Según sus relatos, esta lucha es una de las que más delinea y agudiza la tensión permanente entre la defensa de los derechos colectivos como pueblo y los derechos individuales de las mujeres, donde se disputan los disímiles sentidos de la "violación sexual", la justicia y la unidad.

Los hombres nasa y también varias compañeras, en un acuerdo pocas veces explicitado, han construido un parámetro de valoración y evaluación de las situaciones que pueden llegar a amenazar la unidad. La lucha contra las violencias intradomésticas e intracomunitarias hacia las mujeres nasa, en general, y la "violación sexual", en particular, han sido significadas como una de ellas. Para comprender esto, cobra especial relevancia la definición sobre la información que puede o no circular más allá de las fronteras comunitarias y organizativas, basada en la distinción de los autores de las violencias. Esta aparece condensada en la clasificación entre "violencia interna" (cuando es ejercida por los compañeros-pareja y/o compañeros-comuneros) y "violencia de los actores armados". Esta taxonomía traza los límites del escenario en el cual los hombres y las mujeres nasa vinculan a sus propias prácticas discursivas algunas de las reivindicaciones que esgrimen los organismos de derechos humanos. Dichos límites privilegian las referencias y la visibilidad de la "violencia de los actores armados", reiterada a través del uso frecuente de la expresión "violencia sexual en el marco del conflicto armado", una idea errónea, según considero, devenida en marco interpretativo que enfatiza en la violación sexual ejercida por los actores armados en Colombia, en consonancia con la mirada hegemónica académica y social que ha acentuado la violencia sociopolítica de los últimos setenta años.

26 A partir de la lectura de los trabajos presentados, hay otro tema al que quisiera referirme. Tal vez por coincidencia disciplinar, comparto con Silvana Sciortino el énfasis en las posibilidades que nos ofrece la etnografía para agudizar y contextualizar nuestros 
procesos de comprensión. En particular, considero que el encuentro y la interacción entre los cuerpos de las mujeres nasa y de la investigadora misma se potencian con la etnografía. En el caso que vengo analizando, el trabajo de campo intensivo y la estancia prolongada en el campo así como la relación que fuimos construyendo en el marco de una apuesta por la construcción de conocimiento en colaboración, me permitió compartir la cotidianidad con las compañeras nasa de dos generaciones, comprender sus experiencias y narraciones de violencias y "violación sexual" desde una perspectiva histórica, entender las relaciones que tejen con otros actores y observar y participar en distintas actividades. Pero me posibilitó, sobre todo, acceder a estos planos tan íntimos, entender las complejidades de este tema, comprender las tensiones y contradicciones y abordarlo en un prolongado período de tiempo que abarca desde la década del sesenta del siglo XX hasta la actualidad.

De manera que mi actual comprensión de este campo de conocimiento está fundada en la idea de que el proceso de construcción de conocimiento conjunto para la transformación social tiene lugar durante el trabajo de campo etnográfico, cuya disposición está constituida por y es constitutiva de las acciones de co-descubrir el campo, co-des-cubrirse en él y dejarse interpelar.

Para finalizar, me interesa sugerir para futuros estudios que todavía estamos en deuda con un análisis detallado sobre el proceso histórico de constitución del reactivo clima ideológico hacia el(los) feminismo(s) en las comunidades indígenas del suroccidente colombiano, para así comprender los modos en los cuales se ha configurado un marco de sentido que estigmatiza las luchas contra las violencias hacia las mujeres asociándolas al (los) feminismo(s) y erigiéndolas en una amenaza a la unidad. Este examen, por supuesto, también debe vincular un proceso de autocrítica de las posturas feministas hegemónicas, predominantemente urbanas y eurocéntricas, pues no han logrado construir puentes de diálogo intercultural que privilegien los saberes otros así como las particularidades de los contextos sociales y culturales de las y los sujetos que participan en la interlocución.

Desarrollar una escucha profunda, potenciar la sensibilidad etnográfica, comprender en contexto y humanizar la experiencia de la(s) otra(s) debe constituirse en nuestro horizonte de sentido para continuar con las luchas que las mujeres diversas hemos emprendido en contra de las violencias, el racismo, la discriminación, la injusticia y la exclusión. Sólo así podremos andar el camino para restaurar nuestro propio sentido de humanidad.

\section{Qué nos van a enseñar que no sepamos}

\section{Julieta Paredes}

Las políticas públicas de los gobiernos, de las ONG, de las iglesias, esas miradas colonizadoras, tienen una visión de nosotras, las mujeres indígenas, como de las eternas ignorantes, las tontitas, las incivilizadas; en el "mejor" de los casos somos las ingenuas e inocentes. No es desde la soberbia que decimos y aseveramos esto, aunque suene muy duro: nuestras abuelas nos enseñaron el respeto, pero también la indignación cuando ya llegan a colmos y este es el caso de cómo andan las relaciones entre mujeres, especialmente en el espacio del feminismo eurocentrado, que continúa e insiste en erigirse como el paradigma de las luchas de las mujeres en el mundo, como las 
políticamente correctas. Y no es así, pues cada territorio tiene su historia de luchas y las mujeres de cada territorio por supuesto que también las tienen.

Ya el feminismocomunitario redefinió el feminismo como espacio de encuentro y rendición de cuentas entre mujeres; sin embargo, el feminismo eurocentrado en todas sus versiones -incluidas las anarquistas y las autónomas- se esfuerza por expulsarnos de la discusión, y pretextos no les faltan: desde decir que no hay nada nuevo bajo el sol pues el pensamiento eurocentrado ya pensó en lo que nuestros cuerpos sienten, pasando por legitimar plagios y atizar competitividades y peleas entre indígenas, hasta servirse de calumnias y difamaciones. Es claro que afectamos sus intereses en lo más profundo, pero no deja de indignarnos escuchar las catalogaciones y opiniones sobre nosotras. Existe la convicción de que las mujeres indígenas no nos hubiéramos dado o no hubiéramos podido por nosotras mismas darnos cuenta de nuestras condiciones y situaciones de vida, y que fueran las ONG de género o las feministas y los feminismos los que van a liberarnos, los que van a decirnos que somos personas. Hay condiciones precisamente históricas para que nosotras como indígenas estemos como estamos. Las feministascomunitarias explicamos este hecho a través de lo que llamamos el entronque patriarcal, pero a la vez reivindicamos nuestras luchas que hoy en uno de sus logros tiene al feminismocomunitario como la palabra y la propuesta de mundo desde las luchas de nuestros pueblos y comunidades.

32 Ciertamente hay información que no sabemos ni conocemos, pero cuando estamos hablando de la conciencia de nuestra dignidad, del reconocimiento de que somos gente jaq'e -como decimos en aymara- ¡claro que sabemos quiénes somos y lo que queremos! Nadie nos va a enseñar lo que sabemos desde nuestros cuerpos, nuestras vidas y nuestras luchas ancestrales. Claro que sabemos que nos duele que nos golpeen, humillen y maten a nuestros propios compañeros, pero eso no lo van a decidir desde afuera, desde una neocolonizacion o colonización feminista de nuestros cuerpos; el destino de nuestros cuerpos lo vamos a decidir nosotras, desde las mujeres en nuestras organizaciones y comunidades. Luchando al mismo tiempo contra las injusticias que vivimos hombres, mujeres, personas intersexuales y la naturaleza por parte de un sistema de dominio y hegemonía patriarcal y peleando contra el machismo en nuestras comunidades.

No esperamos que entiendan esto las ONG, los colectivos de feministas, las académicas e intelectuales feministas, pero podrían hacer el esfuerzo, mínimamente reflexionando que las mujeres indígenas somos mujeres y que sabemos que lo somos y sabemos lo que queremos, y no ponerse de juezas de lo que no conocen; desconocen nuestras estrategias, hay mucha soberbia. Creemos que debe plantearse el respeto como base de la relación; sin embargo, esto no se da con el pretexto de que nuestros hermanos indígenas serían unos salvajes y nosotras cómplices o igualmente salvajes como ellos. Nos damos cuenta cómo está tomada a menos nuestra voz para convertirnos en víctimas, y hay algunas indígenas que le hacen el juego a estos conceptos y son las reconocidas, pues cumplen el papel que se espera de nosotras las indígenas, que seamos las que nos quejamos y no las que decidimos, no las que nos defendemos y luchamos.

Me llaman la atención las investigaciones que se hacen sobre nosotras, las mujeres indígenas, y de nuestros pueblos originarios que luchan. Ciertamente no conozco ninguna investigación sobre mujeres blancas o sobre mujeres académicas o mujeres políticas feministas de los partidos burgueses sobre, por ejemplo, la violencia que los hombres blancos y burgueses ejercen sobre ellas y lo que hacen al respecto. Puedo "pecar" de ignorante, pero que yo sepa las luchas las damos las mujeres de a pie, y las mujeres 
intelectuales, de las ONG y mujeres políticas de los partidos hablan a nombre de las pobres mujeres que sufren violencia y no hablan de ellas pues, hasta el momento, ellas no se reconocen "víctimas", pero son presurosas y están a la caza de mujeres indígenas o empobrecidas que se declaran víctimas. El papel de protectoras les encanta y cuando no hay quienes nos declaramos víctimas sino luchadoras que no se dejan, nos descalifican pues no somos financiables. Las que luchan que se las arreglen; a las victimizadas se las financia. Es una nueva relación muy perversa planteada hoy, por ejemplo, en el boom mediático y financiable de "Ni una menos". En contraposición, las mujeres en las luchas de nuestros pueblos no tienen la cobertura mediática.

\section{La academia hoy}

35 Creo necesario señalar que el interés por nuestros pueblos originarios en lo que se refiere a investigaciones académicas es un espacio para la discusión, la reflexión y el cuestionamiento. Nos llama la atención la bibliografía citada en los trabajos aquí planteados - sin duda la consulta de fuentes bibliográficas es una decisión libre, política y no solo académica-. Y con el riesgo de las susceptibilidades que suelen bloquear los espacios de reflexión, queremos manifestar que en general, y en particular, hasta el momento no conocen, o no lo consideran importante, el aporte histórico que hace el feminismocomunitario a la comprensión del lugar de las mujeres denominadas indígenas en las historias del mundo, y no solo de la historia universal, que como su nombre lo dice es uni: es decir habla de una sola versión de la historia.

El feminismocomunitario ya planteó un camino de comprensión de nuestras historias de luchas en el libro Hilando Fino en el año 2009, que inicia el aporte escrito en libros del feminismocomunitario, soporte de documento que va a cuestionar no solo las hegemonías, sino las luchas y el proyecto de mundo que hoy se debate. Sin embargo, se ignoran estos aportes. Adjuntamos y ampliamos una bibliografía que, en los antecedentes, incluso se remite al año 1992. Decíamos que, en general, en la academia hay un desconocimiento del movimiento del "FeminismoComunitario de Abya Yala", y quienes lo conocieron hoy plantean para nosotras la ubicación de lo secundario, de lo derivado, aquel feminismo subalterno, comprendido en otro mayor. Hoy, además de atacarnos, denigran, no sin antes pasarnos por un proceso de plagios, extractivismo intelectual y superficializaciones. ${ }^{\text {ii }}$

La maternidad no deja de ser el intento de entender el camino que hacemos las mujeres indígenas de descolonización de nuestros cuerpos y sobre las prácticas y los pensamientos que de estos nuestros cuerpos emanan, y por eso es valioso ser mujer y ser mujer que lucha en el ámbito típicamente denominado como político.

Sin duda que la maternidad y el cuidado de la vida de las niñas y niños en comunidad cuestiona los parámetros individualistas de una sociedad, de la propiedad privada de los cuerpos, de las wawitas (niñas y niños) como decimos en aymara. Este hecho de partida no significa no cuestionar la violencia normadora de los cuerpecitos que también en nuestras comunidades se da, parámetros de masculinidad y feminidad que también son impuestos a niños y niñas, que los hermanos y hermanas denominan como "complementariedad" hombre-mujer (chacha-warmi). Y eso es lo que nosotras hemos llamado la relación de género indígena y por eso opresora en las relaciones entre hombres y mujeres indígenas. Cierto que las comunidades indígenas traen valores que es 
importante potenciar, pero también es imprescindible asumir una postura crítica al respecto.

Son responsabilidades de la comunidad garantizar la vida que crece, pero eso no garantiza que en última instancia sean los padres y madres que reclamen el cuerpo del hijo o hija para beneficio económico de la familia; son los cruces de las ideologías, pensamientos y decisiones que tomamos mujeres y hombres indígenas en un momento de capitalismo neoliberal que nos empobrece mucho más a nuestros pueblos originarios. Eso es lo que debemos cuestionarnos en cuanto se refiere a las propuestas que tenemos como indígenas; es cómodo reclamar el cuerpo de las wawas para el trabajo de la familia, pero cuán solas y solos se sienten las madres y los padres de los 43 de Ayotzinapa o las madres de desaparecidas y desaparecidos, al momento de reclamar los cuerpos de sus wawitas luchadoras. $O$ cuán solas se sienten las mamás de las hijas que fueron asesinadas por los hombres machistas y femicidas.

\section{La energía convocante del "FeminismoComunitario de Abya Yala"}

40 Precisamente es el feminismocomunitario el que ha propuesto un espacio de discusión y de desafíos descolonizadores que convocan a repensarnos también con las feministas euro-occidentalmente centradas.

Es difícil revolucionar la construcción de saberes solo a partir de la discusión del género, también el cuestionamiento epistémico desde nuestros pueblos tiene que plantearse de manera que sea un dialogo útil para los pueblos del mundo. Lo que denominan la colonialidad del género es útil y es un comienzo, y así es como lo han venido haciendo muchas hermanas indígenas en el continente. Sin embargo, las estrategias fagocitadoras de las academias funcionan de inmediato y las reflexiones de nuestras hermanas indígenas son absorbidas por un ecofeminismo, o son colocadas en feminismos decoloniales o postcoloniales y no dejan de ser estos compartimentos estancos controlados por el pensamiento hegemónico y colonial de Occidente, de donde los feminismos también son parte.

$\mathrm{Ni}$ siquiera la estrategia epistémica del feminismocomunitario se salva de la intencionalidad fagocitaria, sin embargo no es fácil digerir un feminismo que se ubica en el feminismo para cuestionar al propio feminismo como la titularidad y vanguardia de las luchas de las mujeres, o lo políticamente correcto para las mujeres. Por eso hoy el feminismocomunitario es una energía que convoca a la reflexión, a la creación y a la sanación del mundo.

\section{Creatividad y deliberación en las prácticas políticas de las mujeres}

\section{Silvana Sciortino}

43 Al releer mi primer escrito en diálogo con los aportes de las compañeras que participaron en el debate, me sentí interpelada por un compromiso compartido que atraviesa el tema, problema, caso mencionado por cada una. En común encontré la preocupación por dar cuenta de la diversidad de mujeres, historias, trayectorias, luchas, que hacen cotidianamente "al feminismo". En este sentido, aparece la fuerza de la reivindicación 
indígena, nasa, mapuce, andina, comunitaria, latinoamericana, resistiendo a ser apagada en un "deber ser" feminista que se incomoda ante políticas, solidaridades, afirmaciones... "otras".

Muchas vivenciamos el lugar despectivo, peligroso, abyecto, en el cual se nos ubica a las feministas desde sectores o ámbitos varios en nuestra vida cotidiana, trabajo, activismo. Así encaramos luchas locales, en casa, en el movimiento, en el barrio y la comunidad para desandar sentidos peyorativos y estereotipados que limitan nuestras prácticas y dificultan las alianzas entre mujeres. Me refiero a expresiones que nos califican de "locas", "histéricas", "antivarones"... (podría continuar). Me refiero a la angustia de una mujer coya que, durante mi trabajo de campo, me comentó respecto de sus compañeros indígenas: "A mí ya me conocen, ya me dicen feminista, lesbiana, puta, cualquier cosa me dijeron". O cuando otras mujeres emiten expresiones en línea con la citada en mi primer escrito: "el feminismo dispersa sus energías por cualquier lado... Están pensando en algo que no es bueno." En el trabajo de Marcela junto a las mujeres nasa podemos observar la vinculación del feminismo con "el fantasma", con una amenaza "que recorre el norte del Cauca".

Andar y "desandar para andar" podría ser una de las maneras de describir nuestras prácticas feministas. Avanzar en la lucha por nuestros derechos, deseos, emociones, implica al mismo tiempo "volvernos" hacia adentro (de una y de unas), hacia atrás (en la historia), hacia los costados (en nuestros espacios de trabajo, de activismo, familiares) para desenredar los nudos patriarcales que atan nuestras libertades. En ese "andar y desandar", sin poco dolor, hacemos política y generamos solidaridades.

En la primera intervención a este debate sostuve que la organización de las indígenas a partir de su afirmación como mujeres originarias y madres conlleva la vivencia de una serie de tensiones y conflictos intra e intergrupales (tensiones que las mujeres no indígenas también conocemos y con los cuales lidiamos). Los trabajos de María Cristina y Marcela dan especificidad a esta afirmación, exponiendo una serie de conflictos que las mujeres debieron afrontar y resolver para transformar contextos opresivos al interior de sus pueblos. ¿Qué sucede cuando la reivindicación de un colectivo de "originarias" acontece en el marco de un espacio del "movimiento amplio de mujeres"? (Molyneux 2003).

47 Las mujeres indígenas sobre las cuales desarrollé mi primer artículo participan o han participado de los Encuentros Nacionales de Mujeres, en especial en el taller de las "Mujeres de los pueblos originarios".iii Este conforma una reunión a nivel nacional donde se comparten experiencias, denuncias, se acuerdan acciones. Allí las "originarias" construyen posicionamientos frente a las mujeres no indígenas. Ante esta dinámica particular conforman una identidad que se afirma a partir de un acuerdo que logra conciliar (de manera inestable y en continuo cambio) la pluralidad en su interior. La noción de "hermanas" es una de las claves que, junto a la noción de "Pueblo", funcionan logrando unidad. Los reclamos por territorio y por la recuperación de la cosmovisión son dos ejes de sus reivindicaciones que permiten reunirlas en una lucha más allá de las distancias geográficas, diferencias culturales, trayectorias personales y perspectivas políticas. La historia es colectiva, es la historia de los Pueblos la que se reivindica, es la historia y el presente de resistencia a la colonización lo que las hermana. Ahora bien, como toda identidad, además de ser construida, debe ser resguardada ante las tensiones, aceptando reacomodaciones internas y encarando las articulaciones con actores externos. 
Desde esta identidad, enraizada en la noción de Pueblo, es que se presentan en el movimiento de mujeres.

Esta modalidad de participación colectiva pone en evidencia su eficacia al resguardar la especificidad en términos culturales que las originarias proponen reivindicar en este movimiento diverso. Pero por momentos también genera distancias que parecen irreconciliables, rispideces al momento del intercambio y la construcción colectiva con "otras" mujeres. Los momentos de desacuerdo o de dificultad para mantener el diálogo son frecuentes. En estos conflictos suelen imperar ciertos estereotipos. Como referí anteriormente, algunas voces indígenas rechazan a las feministas por ser parte de un movimiento "occidental", "de mujeres blancas", "colonial", "racista". En los primeros talleres que participé aún algunas mujeres indígenas se referían a las no indígenas como "las winkas", con las connotaciones negativas que esa expresión contiene. No es la ingenuidad lo que me conduce a realizar este tipo de señalamientos, conozco y repudio el genocidio y el racismo del blanco, del colonialismo, del patrón de poder colonialmoderno. Pero en la coyuntura de un encuentro de mujeres "otras" (indígenas y no indígenas), muchas nos proponemos, de mínima, el desafío de romper con estereotipos que nos habilite al diálogo.

La continuidad de esas reuniones fue exponiendo la necesidad de construir solidaridades, intervenciones y prácticas colectivas que nos acerquen. Sobre las voces indígenas dominantes del taller, las cuales imponían como única prioridad el debate sobre territorio y tierras, identidad y cosmovisión, se comenzaron a oír otras realidades por las cuales luchar. Entre ellas la violencia, la legalización del aborto, las relaciones de desigualdad en el movimiento indígena fueron ganando lugar y encontrando apoyo en las trayectorias de mujeres feministas. En este camino de ruptura de estereotipos, los feminismos "otros" tienen la posibilidad de ser escuchados y conocidos por colectivos de mujeres que guardan recelos ante las mujeres que nos definimos feministas.

50 Cabe mencionar también que la verticalidad desde la cual mujeres no indígenas proponen "ayuda" y "asistencia" choca contra la fuerza de mujeres latinoamericanas que toman la palabra para proponer luchas conjuntas. Resabios asistencialistas que aún se oyen en algunas intervenciones se debilitan ante feministas que, como describió Mariana en la introducción, nos preocupamos por acercarnos a la realidad de las mujeres indígenas buscando ejercer la menor violencia epistémica posible y descentrándonos de nuestro eurocentrismo latinoamericano y de los lugares privilegiados de enunciación. Feministas que nos oponemos a las tramas coloniales al interior del propio movimiento, que discutimos con las miradas monolíticas construidas sobre las mujeres, que desafiamos formulaciones moralistas, salvacionistas de quienes suelen ser definidas como "las otras" del feminismo.

51 La convicción por un saber y una práctica política descolonizadora nos alienta hacia la construcción de puentes entre mujeres con trayectorias diversas. Los lazos solidarios pueden nacer del reconocimiento de la creatividad desde la cual las mujeres hemos conseguido organizarnos, resistir, modificar vínculos opresivos. En el primer texto me ocupé de exponer desde un caso concreto que "la política" requiere de creatividad en las formas de desafiar los lugares preestablecidos y las limitaciones que vivimos como mujeres indígenas, mujeres latinoamericanas... La maternidad ha funcionado para algunas como un nexo entre el trabajo reproductivo y las prácticas políticas. Los trabajos de Julieta, Marcela y María Cristina comparten la creatividad de mujeres que localmente construyen sus prácticas colectivas. Las nasa que en su lucha contra la violencia "no están 
amenazando la unidad, sino transformándola"; la construcción de una perspectiva mapuce de género"; el pasaje reflexivo de las feministas "andinas" hacia un "feminismo comunitario".

52 La creatividad en la construcción de "la política" no es el único elemento que encuentro enlazando las distintas intervenciones en este debate. La deliberación interna también está presente. Los dos modelos de maternidades políticas que defino en el primer artículo dan cuenta de voces disonantes en una trama identitaria que posee interlocutores desigualmente posicionados. Lo que se enuncia en determinados escenarios es producto (no acabado) de deliberaciones internas. Las indígenas vienen debatiendo y algunas han encontrado formas de resignificar las costumbres y transformarlas en posibilidad de participación en el movimiento.

Esas mujeres indígenas que acuerdan la relevancia de ser una voz más en el movimiento amplio de mujeres, toman posiciones y construyen vínculos deliberando entre ellas. Un caso posible lo pudimos observar en el taller cuando mujeres no indígenas y un sector minoritario de mujeres originarias plantearon la necesidad de debatir respecto a la legalización/despenalización del aborto. Las voces que en una primera instancia se mantuvieron en oposición frente a la incorporación de este tema como propio de un taller de mujeres originarios se fueron moderando. Año tras año, su firme determinación de no abordar el tema fue rotando en solidaridad con las mujeres que han abortado:

No estamos demonizando a las hermanas que practiquen el aborto porque sabemos que eso tiene que ver con una decisión desgarradora y extrema, pero tampoco desde el taller de pueblos originarios, sería una aberración que nosotros estemos defendiendo y propagando eso [se refiere al aborto]. Sí respetamos y no criminalizamos a las hermanas que lo practiquen (Sciortino 2014).

Las experiencias de trabajo de mis compañeras en debate muestran, en mi opinión, procesos que reúnen a mujeres indígenas, feministas, en espacios de intercambio, deliberación y búsqueda creativa de enfrentar las múltiples opresiones de las mujeres en un sistema patriarcal capitalista y heteronormativo.

Las mujeres lidiamos cotidianamente con "costumbres", "tradiciones", representaciones que nos ubican en lugares vulnerables. Si aceptamos que la tradición y las costumbres son creaciones con intereses políticos determinados e históricamente situadas, o nos afirmamos desde una identidad en tanto reinvención en lugar de recuperación de un pasado mítico homogéneo (Sierra 1997, p. 133), nuestras posibilidades de acción se multiplican. Una práctica feminista descolonizadora tendría que proponerse, en mi opinión, el resguardo de la "capacidad deliberativa" (Segato 2011) que hace a los sujetos colectivos. En especial cuando el feminismo se construye entre mujeres de culturas subalternas. Esta propuesta poco tiene de armónica y mucho de conflictiva, pero la experiencia muestra su potencial para la ruptura de las barreras que parecen volvernos radicalmente otras.

En nuestras prácticas, descolonizar el feminismo nos compromete en el reconocimiento de la creatividad donde la hegemonía subestima o condena. Descolonizar involucra el apoyo a la deliberación en pos de la transformación de nuestras culturas evitando la imposición externa de voces que se autoproclaman las indicadas para guiar los procesos de liberación locales. Como sostiene Julieta para el colectivo de feministas comunitarias, el feminismo es "la lucha de cualquier mujer", "en cualquier tiempo de la historia". En esta expresión se puede buscar la clave para poblar el feminismo de experiencias locales, de mujeres que intentan, de logros parciales, de libertades en movimiento... 


\section{Reflexiones finales de la coordinadora}

\section{Mariana Daniela Gómez}

57 En los últimos años se abrió y se instaló un debate al interior de los feminismos que piensan "la diferencia" (Hernádez Castillo 2004; Femenías 2013, Espinosa 2011) y han surgido otros feminismos que plantean su disidencia con el "feminismo occidental". Sin embargo, todavía este sigue siendo un debate entre académicas feministas, muchas de ellas también activistas o militantes, al menos en las academias de América Latina y América Central.

Hemos convocado a este debate para entablar un diálogo entre feministas académicas (y activistas) y mujeres originarias activistas ( $\mathrm{y}$, en algunos casos, también académicas). Aquí se han manifestado cuatro voces, cuatro intervenciones, dos de ellas de mujeres originarias, aymara y mapuce, y dos no originarias provenientes de Argentina y de Colombia. Varios de los interrogantes que nos movilizan los recogimos en la introducción, convocando con preguntas impacientes y ansiosas. Esta curiosidad responde menos a una pulsión académica-teórica que a una política. Varias de quienes venimos siguiendo estos temas, o hemos acompañado procesos organizativos de mujeres indígenas, deseamos saber si las originarias organizadas y politizadas de múltiples maneras podrán sustraerse del feminismo popular que se está gestando en las calles, plazas, barrios y casas de Argentina. No nos importa (a algunas nunca nos importó demasiado) dónde hay que encuadrar las luchas, intereses y reclamos de las mujeres originarias, si estos son "estratégicos" o “prácticos" (Molyneaux 2003). Como dice Gisela Espinosa, si nos quedamos en esa pregunta quedaremos estancadas en una falsa disyuntiva. Hay que aprender a sustraerse del tiempo lineal y ascendente que el feminismo heredó de la izquierda y del marxismo, como si una vertiente condujera necesariamente a la otra o como si los territorios no tuvieran distintos tiempos (Julieta). “¿Para las campesinas e indígenas será demanda práctica o estratégica el acceso a la tenencia de la tierra?" (Espinosa 2011, p. 22). El famoso modelo de Molyneaux (2003) no parece muy útil, dado que las necesidades se comprenden en el marco de las historias locales y dentro de marcos culturales, sociales y políticos específicos. La tenencia de la tierra les habilita a las campesinas e indígenas una serie de nuevos posicionamientos que rebasan completamente su condición de género previa.

Parece ser que el "feminismo de la igualdad" (el mismo que Cristina denomina feminismo liberal y Julieta feminismo eurocéntrico) o la igualdad como un universal al que las mujeres indígenas deberían ingresar o que en algún momento "les va a llegar" es, como señala María Luisa Femenías (2013, p. 203), un "no-lugar" pero que las obliga a confrontarse y reflexionar sobre las costumbres y tradiciones de sus comunidades y pueblos.

60 Este debate nos ha mostrado que existen mujeres indígenas que están embarcadas en la investigación y la producción de otras teorías de género, reflexionando en torno a las actuales prácticas de "recuperación" de antiguas normativas de género del mundo indígena precolonial, desde los aportes de los feminismos postcoloniales que se proponen descifrar los posibles impactos que ha tenido "la colonialidad del género" (Segato 2011) y desde sus propias experiencias, es decir, desde sus "cuerpos-territorio" (Cristina). 
También que en América Latina existen mujeres originarias que se definen como feministascomunitarias:

¿Por qué entonces somos feministas? Porque los significados de las palabras están ligados a las experiencias históricas, tanto de la memoria larga como de la memoria corta de los pueblos y sus gentes. Por eso en ese camino de entender quiénes somos, hurgamos en la historia y encontramos una contemporaneidad de contestaciones y acciones políticas contra el sistema patriarcal por parte de las mujeres en nuestro continente también. Acciones triplemente invisibilizadas y casi destruidas, las trazas que dejaron nuestras tatarabuelas, hoy tan difíciles de encontrar. Somos feministas porque feminismo para nosotras significa la resistencia, la lucha y la propuesta de cualquier mujer en cualquier parte del planeta ante el patriarcado depredador de todo lo que vive y lucha por vivir. Entonces no hay fundadoras de esta acción histórica de las mujeres sino diferentes expresiones contemporáneas unas de otras (aunque la una no sepa de la otra) en otras partes del planeta y lugares en los que el patriarcado se haya iniciado. Lo que sí hay es una etapa histórica en la que aparece el nombre de feminismo signando un deseo de coordinar internacionalmente las diferentes expresiones de esta lucha heredada entre nuestras tatarabuelas. Que aparezca el nombre en un determinado idioma y un determinado lugar no niega la práctica anterior, acciones en otros lugares que dieron como resultado nombres, conceptos y teorizaciones. Es esa vertiente de prácticas y acciones que hoy recogemos y hacemos nuestra raíz. (Paredes 2006, p.77-78)

61 Silvana Sciortino, feminista activista en las calles pero también en la academia, siguió de cerca los procesos de reflexión y debate -especialmente en el marco de los Encuentros Nacionales de Mujeres- de originarias de diversas procedencias. En su primera intervención nos muestra cómo la maternidad se conforma en un lugar de lucha, en pretexto y legitimación para reforzar roles viejos (los asignados por la tradición) y crear nuevos (en las organizaciones y movimientos indígenas). La mujer originaria en tanto "madre" es pensada y analizada como una forma de participación política (de politizarse) que las mujeres indígenas han construido en el marco de la movilización social en Argentina. Este rol de madre puede activar significados en dos direcciones distintas: hacia una tendencia conservadora que reifica a la mujer indígena en el trabajo reproductivo y en el espacio doméstico y, en la otra dirección, hacia una maternidad colectiva donde las originarias se posicionan como responsables de la reproducción, pero también como partícipes de las luchas de sus pueblos en el ámbito político público. La maternidad y sus responsabilidades asociadas las "proveen de un modelo para entrar en la lucha política pública de sus pueblos.” ¡Pero cuidado! Pues esta misma imagen de la mujer indígena como una madre que abriga a su familia, a su pueblo y a la naturaleza, puede troquelarse en una mujer indígena hiperreal o "enlatada", dice Silvana (o de "película", digo yo) y ser funcional a "una agenda global despolitizada y alejada de las luchas locales situadas en los países no hegemónicos". Más allá de esto (o por eso mismo), Sciortino propone que generemos "marcos de pensamiento no prescriptivos" dentro del movimiento feminista, que salgamos del "deber ser" feminista para poder comprender los posicionamientos de las originarias que recién están comenzando a revisar sus lugares en sus familias, comunidades, organizaciones y dentro de sí mismas, escuchando sus voces internas, armándose relatos, narrativas, biografías, estelas, hitos y tiempos en las historias de sus pueblos que les han transmitido. Creatividad y Deliberación entonces pues...

62 Marcela Amador Ospina nos narra cómo en el norte del Cauca el feminismo es figurado como "un fantasma" que amenaza la unidad del movimiento indígena. Allí las mujeres nasas vienen conviviendo, padeciendo, soportando, resistiendo y conceptualizando las 
experiencias de violencia sexual intracomunitarias y otras perpetradas por hombres de afuera. Aunque muchas nasas no se designen como feministas - por desconocimiento y prejuicio, por temor a las connotaciones y al estigma que podría pesarles o por elección meditada-, todas destacan los cambios que han traído a sus vidas las capacitaciones sobre "perspectiva de género" y "derechos de las mujeres" en un conjunto de programas y espacios ofrecidos por el Estado, organizaciones indígenas, civiles y también por las malditas ONG. Una de sus interlocutoras, durante su trabajo de campo, le explica con claridad que las formas de participación política y de organización que se dan las mujeres nasas varían de acuerdo al contacto que tuvieron con organizaciones de mujeres feministas que trabajaron en la región. Entablar diálogos sobre la violencia sexual implica entablar otros sobre las concepciones culturales acerca de las relaciones de género en estos pueblos. El principio de la complementariedad como un rasgo del Pueblo Nasa es un discurso reproducido por las organizaciones y la dirigencia indígena pero bastante ausente en los relatos cotidianos de las mujeres. Muchas no caracterizan ciertas experiencias que las no indígenas experimentaríamos como actos de "violencia sexual intradoméstica", y existe toda una división entre aquellas mujeres que llaman a eso violencia y se disponen a denunciarlo y las que no. "Escuchar y humanizar sus experiencias" nos aconseja Marcela, si queremos preservar nuestros lugares de interlocución (y comprometernos con sus tiempos).

María Cristina Valdez nos habla y nos interpela (porque ella ha sido también interpelada por sus compañeras de pueblo) desde un lugar de enunciación propiamente mapuce para presentar reflexiones y conceptos sobre una "teoría de género mapuce" (o toda una arqueología) que busca anclarse en la cosmovisión que organiza ese "mundo" del cual ella viene, a lo que sumará aportes de los estudios de colonialidad y postcolonialidad, herramientas necesarias para logar "... un posicionamiento crítico y decolonial acerca de cómo pensar el género en las sociedades preexistentes a los estados-nación”. En su propuesta, lo espiritual (toda dimensión a etnografiar que nos plantea nuevos desafíos) es una dimensión que anima las experiencias de género, cuestión que ella seguirá explorando, partiendo de que hay una concepción del género que insiste en no amoldarse al canon académico del "construccionismo social". El texto de Cristina tiene algunos puntos en común con el de Julieta Paredes (además de que ambas se reconocen indígenas), como cuando caracterizan las relaciones de género pre-coloniales como asimétricas (Cristina) o "patriarcales originarias" o de "entronque patriarcal" (Julieta), cuando coinciden en señalar que la colonialidad del género (Segato 2011) es una categoría que les permite pensar las maneras en que las jerarquías y desigualdades entre los géneros se agravaron con la colonización y sobre la necesidad de un pensamiento propio de/desde las mujeres indígenas para enunciar estos procesos. Las mujeres originarias también sufren femicidios en el Wallmapu y se mueren por el avance del modelo neodesarrollista, siendo Vaca Muerta alumna ejemplar en la encarnación de este modelo. Una referente emblemática, Cristina Linkopan, cuya lucha contra ese modelo reivindican y recuerdan muchas originarias organizadas del sur del país, falleció a causa de un cáncer aparentemente producido por la contaminación de su cuerpo-territorio. Julieta Paredes, partícipe años atrás del colectivo/comunidad boliviano Mujeres Creando y actualmente del espacio Asamblea Feminista, nos revela que antes de que el feminismo postcolonial y descolonial se pusiera de moda entre las feministas académicas de Argentina, antes de que esta discusión y las acusaciones al feminismo hegemónico se hicieran sentir...antes de todo ("en los orígenes") ya estaba Mujeres Creando en las calles 
(no en el Gobierno, no en la academia, no en las ONG), problematizando e interviniendo en mundos neocoloniales complejos y abigarrados, buscando alianzas con mujeres diversas, interpelando a la sociedad boliviana a pensarse y rompiendo esquemas mediante performances y acciones callejeras. Julieta Paredes denomina patriarcado a las dinámicas de las relaciones de género pre-conquista y denuncia el patriarcado de sus aliados indígenas (Monasterios 2006, p. 156).

¿Bajo cuáles coordenadas sería posible recrear una práctica subversiva como la que incubó Mujeres Creando en La Paz (conscientes de la herida colonial) a un país como Argentina donde hombres, mujeres y jóvenes indígenas actualmente se están reuniendo para aproximarse a un entendimiento de lo que hizo el Estado argentino con los pueblos originarios a fines de siglo XIX, usando el término genocidio? ¿Cómo es la herida de la conquista y la colonización en las vidas pasadas y presentes de las mujeres originarias aquí en Argentina? ¿Qué sangra por esa herida en nuestro territorio austral? En abril de 2015 un colectivo de mujeres llamado Marcha de Mujeres Originarias, coordinado por la activista mapuce Moira Millán (2016) salió a las calles de la Ciudad de Buenos Aires, acompañadas por unas diez mil personas. Fue la primera vez que algunas docenas de mujeres indígenas de Argentina se organizaron para hacer una acción colectiva de estas dimensiones. "Sin nosotras no hay país" fue una de sus consignas.

\section{Complementariedad, feminismos otros y perspectivas situadas: puntos de encuentro}

1) La Complementariedad al debate: las cuatro intervenciones se detienen en este concepto/categoría/representación/idea un tanto estelar, problemático y seductor por portar pasaporte de existencia pre-colonial. Todas tienen algo para decir puesto que parece ser una parada obligada. Posiblemente sean necesarias investigaciones dedicadas a diversas arqueologías sobre los orígenes, usos y difusión de este concepto en el pasado y en la contemporaneidad pues, como dice Marcela:

este discurso no es primordial en el tiempo, sino que tiene un autor contemporáneo, es fundamental comprenderlo en su dimensión histórica, así como en su proceso de constitución y reconfiguración en el marco de diálogos e intercambios interculturales entre diferentes sujetos ubicados de maneras desiguales en el escenario.

Algo de esto me recuerda a aquel debate sobre los "orígenes de la dominación masculina" en la "historia de la humanidad" en el que se enredaron durante años las antropólogas feministas en la década del 70 sin encontrar una única respuesta o modelo que las satisficiera. ¿Algo ya tuvo que existir en el pasado para poder crearlo o recrearlo en el presente? La complementariedad como algo preciado que se perdió durante la colonialidad del género y que se podría recuperar. Cristina señala que a las mujeres indígenas demasiado se les "cuestiona el uso de categorías propias para defender nuestras posturas, sea por su conservadurismo y/o falta de sustento en fuentes históricas que evidencien su autenticidad"; también que la dualidad en la complementariedad incluye la ambivalencia, la movilidad y la transitoriedad, y que dualidad excede a la humanidad; el "recurso" a la cosmovisión también está atado a sentidos de emancipación y no solo es una actitud cosificadora, y que los conceptos de complementariedad y dualidad también están en discusión y disputa al interior de los movimientos y organizaciones indígenas porque hay una memoria en juego que también se disputa. Silvana nos cuenta que las referencias a la "complementariedad" se las ha escuchado a algunas de sus interlocutoras 
en los ENM. La complementariedad también es una de las banderas que enarbolan en sus discursos igualitaristas las organizaciones indígenas del Cauca, y que muchas mujeres probablemente repliquen. Pero pareciera ser que se trata, según Marcela, de "un régimen de heterosexualidad obligatoria". Además, el discurso de la complementariedad es ajeno a los pueblos indígenas de Colombia y habría llegado a través de la adopción que hicieron intelectuales nasas cuando estudiaron en Bolivia hace algunas décadas atrás. Julieta Paredes, en el primer texto, cuestiona la idea de complementariedad y lo ve como parte del vocabulario patriarcal de las dirigencias indígenas... La complementariedad en el mundo andino como parte del orden simbólico antiguo, precolonial y patriarcal. Cuidado, nos advierte ella, que se puede ser complementario y patriarcal sin ningún problema.

2) Encuentros y desencuentros de las mujeres indígenas con los feminismos: Marcela nos cuenta sobre el clima reactivo y conservador contra toda idea y práctica asociada al feminismo ya que este es "un fantasma que amenaza la unidad", y esto ocurre a tal extremo que el cuestionamiento a la violencia sexual intracomunitaria y doméstica también es perseguida, desdeñada, insignificada, ninguneada:

Me interesa sugerir para futuros estudios que todavía estamos en deuda con un análisis detallado sobre el proceso histórico de constitución del reactivo clima ideológico hacia el (los) feminismo(s) en las comunidades indígenas del suroccidente colombiano, para así comprender los modos en los cuales se ha configurado un marco de sentido que estigmatiza las luchas contra las violencias hacia las mujeres asociándolas al(los) feminismo(s) y erigiéndolas en una amenaza a la unidad.

71 Cristina plantea una disputa de saberes trayendo algunas joyitas de lo que pueden aportar las mujeres indígenas cuando se proponen reflexionar sobre las concepciones de género de sus pueblos y organizaciones, y se manifiesta contra el feminismo igualitarista liberal. Julieta empalma una crítica más virulenta a las feministas eurocentradas y su accionar dentro de las ONG que en el proceso de institucionalización del género han fagocitado la radicalidad política del término. No obstante, creo que las fuertes críticas de Julieta deben ser situadas en el contexto boliviano de las últimas dos décadas que ella y otras de sus compañeras y aliadas se han dedicado a caracterizar en múltiples escritos. Y cuidado con apropiarse de esta crítica de manera fácil (precisamente por su radicalidad política que seduce, por su autonomismo) para volverla un argumento replicado hasta el hartazgo en artículos y congresos en Argentina. Un año y medio atrás escribíamos con Silvana Sciortino (Gómez y Sciortino 2015) que en nuestro país los procesos de acompañamiento y capacitación con mujeres indígenas realizados por técnicas de ONG y de programas del Estado habrían comenzado en los 90; todavía son escasos y allí se han iniciado algunas discusiones y diálogos entre mujeres de diversas procedencias en torno a las violencias machistas, las desigualdades de género y el derecho a decidir sobre los cuerpos propios. Sería desafortunado tachar de manera simplista a esas mujeres de "feministas hegemónicas apresuradas por salvar a las mujeres subalternas". Tal vez allí encontremos alianzas invisibles a las discusiones académicas apresuradas. Por último, Silvana menciona desde un comienzo las dificultades para establecer puentes entre mujeres feministas organizadas desde los florecientes feminismos no hegemónicos (y ansiosas por ese diálogo con las originarias) y las propias indígenas que insisten en la idea de que el feminismo es un movimiento colonizador, invasivo y de mujeres de clases media y alta. La autora insiste en "la necesidad de construir solidaridades, intervenciones y prácticas colectivas que nos acerquen". 
72 3) Perspectivas situadas (posicionamientos epistemológicos-políticos): todas escriben situadas en/desde los feminismos no hegemónicos, pero en feminismos que se ubican dentro de los feminismos (el feminismocomunitario) para plantear críticas y cuyo punto de partida es el reconocimiento de los procesos de colonización por los que atravesaron los pueblos indígenas y las mujeres de estos pueblos. Marcela se reconoce feminista y se sitúa en las experiencias de investigación para la acción (IAP) y en el diálogo intersubjetivo, una propuesta de investigación en función de la demanda, una investigación conceptualizada también como una acción política; el trabajo de campo etnográfico es "un lugar" óptimo para la construcción de conocimientos con otras mujeres para la transformación social y de ellas mismas, de todas: desarrollar una escucha profunda, potenciar la sensibilidad etnográfica, comprender en contexto y humanizar la experiencia de la(s) otra(s). María Cristina hace antropología de género en su propio pueblo y "por demanda", trabajo que se toma muy en serio pues entiende "que la dimensión político epistemológica es la que define una resolución creativa y afirmativa de las identidades de las mujeres como colectivo". Silvana sostiene que "la convicción por un saber y una práctica política descolonizadora puede pensarse como un puente entre mujeres con trayectorias diversas" en el marco de los feminismos no-hegemónicos. El feminismocomunitario que nos explica Julieta contribuye a la descolonización del feminismo, abre la definición y complica sus orígenes (el feminismo ha dejado de ser un invento de las mujeres europeas); evoca, recuerda y valora las luchas y sabidurías de las mujeres latinoamericanas, indígenas rebeldes y anarquistas bolivianas contra el patriarcado. Y advierte que para descolonizarse hay que despatriarcalizarse, y que esto no se puede comenzar sin cuestionar también a los hermanos indígenas y a los discursos indianistas (Schiwy 2006).

\section{BIBLIOGRAPHY}

Comisión Memorias. (1997). Memorias VII Encuentro Latinoamericano y del Caribe. Cartagena-ChileSantiago.

Espinosa, G. (2011). Cuatro vertientes del feminismo en México. Diversidad de rutas y cruce de caminos. México: UAM-Xochimilco.

Espinosa, Y., Gómez Correal, D. y Ochoa Muñoz, K. (2014). Tejiendo de otro modo: Feminismo, epistemología y apuestas decoloniales en Abya Yala. Universidad del Cauca: Popayan Editorial.

Femenías, M. L. (2013). El género del multiculturalismo. Bernal: UNQUI.

Gargallo, F. (2014). Feminismos de Abya Yala. México: Editorial Corte y Confección. Primera edición digital.

Gómez, M. y Sciortino, S. (2015). Mujeres indígenas, derechos colectivos y violencia de género. Intervenciones en un debate que inicia. Revista Entramados y perspectivas de la carrera de Sociología, 5, 37-63. 
Hernández Castillo, A. (2004). Descentrando el feminismo: Lecciones aprendidas de las luchas de las mujeres indígenas. En Congreso Anual de la Asociación Latinoamericana de Ciencias Políticas (ALACIP). México.

Machado Aráoz. H. (2014). Territorios y cuerpos en disputa. Extractivismo minero y ecología política de las emociones. Intersticios, Revista Sociológica de Pensamiento crítico, 7, 56-71.

Millán, M. (2016). El femicidio de mujeres indígenas en la Argentina. Disponible en: http:// www.mapuexpress.org/?p=1938

Molyneux, M. (2003). Movimientos de mujeres en América Latina. Estudio teórico comparado. Madrid: Ediciones Cátedra.

Monasterios, E. (2006). Los desafíos del feminismo autónomo en sociedades que arrastran pasados coloniales. En E. Monasterios (Ed.), No pudieron con nosotras, el desafío del feminismo autónomo de Mujeres Creando, (pp. 153-171). La Paz: Plural Editores.

Paredes, J. y Galindo, M. (1992). Y si fuésemos una espejo de la otra, por un feminismo no racista. La Paz: Mujeres Creando.

Paredes, J. (2006). Para que el sol vuelva a calentar. En E. Monasterios (Ed.), No pudieron con nosotras: el desafío del feminismo autónomo de Mujeres Creando, (pp. 61-96). La Paz: Plural Editores.

Paredes, J. (2010). Hilando fino, desde el feminismo comunitario. La Paz: Mujeres Creando Comunidad. Paredes, J. y Guzmán, A. (2014). El tejido de la Rebeldía. La Paz: Mujeres Creando Comunidad. Paredes, J. (2016). El desafío de la Despatriarcalización. La Paz: Feminismo Comunitario de Abya Yala. Schiwy, F. (2006). "No queremos ser un capítulo en tu libro". Notas sobre heterogeneidad, colonialidad y zonas refractarias. En E. Monasterios (Ed.), No pudieron con nosotras: el desafío del feminismo autónomo de Mujeres Creando, (pp. 173-205). La Paz: Plural Editores.

Sciortino, S. (2014). Violencias relatadas, derechos debatidos y mujeres movilizadas: el aborto en la agenda política de las mujeres indígenas en Argentina. Revista Caravelle, 102, 87-106.

Sciortino, S. (2015). Procesos de organización política de las mujeres indígenas en el movimiento amplio de mujeres en Argentina. Consideraciones sobre el feminismo desde la perspectiva indígena. Revista Universitas Humanística, 79, 65-87.

Sciortino, S. (2015). Políticas de Identidad en los Encuentros Nacionales de Mujeres (Argentina): momentos coyunturales en la conformación de una agenda política. Revista Vía Iuris, 22, (en prensa).

Scott W., J. (2006). Historia del Feminismo. En M. T. Hernández (Ed.), Orden social e identidad de género, (pp. 10-29). México: Universidad de Guadalajara- CIESAS.

Segato, R. (2010). Género y colonialidad: en busca de claves de lectura y de un vocabulario estratégico descolonial. En A. Quijano y J. Mejía Navarrete (Eds.), La cuestión descolonial. Lima: Universidad Ricardo Palma - Cátedra América Latina y la Colonialidad del Poder.

Segato, R. (2011). Género y colonialidad: en busca de las claves de lectura y de un vocabulario estratégico descolonial. En K. Bidaseca y V. Vazquez Laba (Comps.), Feminismo y Poscolonialidad. Descolonizando el feminismo desde y en América Latina, (pp.17-48). Buenos Aires: Ediciones Godot.

Sierra, M. T. (1997). Esencialismo y autonomía: paradojas de las reivindicaciones indígenas. Alteridades, 7 (14), 131-143. 


\section{ENDNOTES}

i. En otro lugar analicé las perspectivas sobre relaciones de género en los pueblos indígenas de América Latina, principalmente aquellos pertenecientes a la zona andina y mesoamericana (Amador Ospina, en prensa).

ii. Ver Francesca Gargallo (2014) y Yuderkys Espinosa Miñoso, Diana Gómez Correal y Karina Ochoa Muñoz (2014).

iii. En otros trabajos di cuenta de la historia de conformación de este taller y de las mujeres que lo conforman (Sciortino, en prensa). 